\title{
Determinação dos valores energéticos e aminoacídicos da silagem de grãos úmidos de milho para frangos de corte
}

\author{
Frank, R. ${ }^{\text {; }}$ Nunes, R.V. ${ }^{1}$; Schone, R.A. ${ }^{\text {; }}$ Pires Filho, I.C. ${ }^{\text {; }}$ Silva, I.M. ${ }^{1}$ e Castilha, L.D. ${ }^{\circledR}$
}

'Departamento de Zootecnia. Universidade Estadual do Oeste do Paraná. UNIOESTE. Paraná. Brasil.

2Departamento de Zootecnia. Universidade Estadual de Maringá. UEM. Maringá. Paraná. Brasil.

\section{PaLAVRAS CHAVE ADICIONAIS}

Alimento conservado.

Aves.

Digestibilidade.

\section{ADDITIONAL KEYWORDS}

Conserved feed.

Birds.

Digestibility.
INFORMACIÓN

Cronología del artículo.

Recibido/Received: 02.06.2015

Aceptado/Accepted: 11.01.2016

On-line: 16.03.2016

Correspondencia a los autores/Contact e-mail:

leandrocastilha@hotmail.com

\section{RESUMO}

Para a determinação dos valores energéticos da silagem de grãos úmidos de milho (SGUM), foram utilizados 120 frangos de corte machos, linhagem Cobb Slow, de 21 a 31 dias de idade, com peso médio inicial de $765,0 \pm 1,7 \mathrm{~g}$, distribuídos em um delineamento inteiramente casualizado, com cinco tratamentos (ração referência-RR e níveis de substituição da SGUM de 10, 20, 30 e 40\%), seis repetições e quatro aves por unidade experimental. O período experimental teve duração de dez dias, sendo cinco de adaptação e cinco de coleta. $O$ método de análise foi o de coleta total de excretas, para posterior análises de energia metabolizável aparente (EMA) e EMA corrigida pelo balanço de nitrogênio (EMAn) da SGUM. Para a determinação dos valores de aminoácidos, foi usada a técnica de alimentação forçada em 12 galos Leghorn cecectomizados, com peso médio de $1912,10 \pm 133,73 \mathrm{~g}$. Seis animais receberam a SGUM e os outros seis permaneceram em jejum. Ao final do período de coleta de excretas, foi determinado o perfil de aminoácidos essenciais, coeficientes de digestibilidade verdadeira e o conteúdo digestível verdadeiro dos aminoácidos no alimento. A SGUM apresentou valores médios de EMA e EMAn de 2283 de $2272 \mathrm{kcal} / \mathrm{kg}$, respectivamente, sendo que os valores energéticos foram negativamente influenciados pelos níveis de inclusão da SGUM. A cistina apresentou o menor coeficiente de digestibilidade, enquanto a leucina e a glutamina apresentaram os maiores valores de aminoácidos digestíveis.

\section{Determination of energy values and amino acids in high moisture corn silage for broilers}

\section{SUMMARY}

To determine the energy values of high moisture corn silage (SGUM), 120 Cobb Slow male broilers from 21 to 31 days old, with an initial average weight of $765.0 \pm 1.7 \mathrm{~g}$, were used, distributed in a completely randomized design, with five treatments (reference ration-RR and replacement levels of SGUM 10,20,30 and $40 \%$ ), in six replicates of four birds each. The experimental period lasted for ten days, five for adaptation and five for collection. The method of analysis was the total excreta collection for the subsequent analysis of its apparent metabolizable energy (EMA) and nitrogen corrected EMA (EMAn) of SGUM. To determine the amino acid values, the technique of forced feeding was applied in 12 cecectomized Leghorn roosters, with an average weight of 1912.10 $\pm 133.73 \mathrm{~g}$. Six animals received SGUM and the other six were fasted. At the end of the excreta collection period, the essential amino acid profile was determined, as well as, the true digestibility coefficients and the true digestible content of amino acids in the feed. SGUM presented average values of EMA and EMAn of 2283 and $2272 \mathrm{kcal} / \mathrm{kg}$, respectively, and the energy values were negatively affected by the inclusion levels of SGUM. Cystine presented the lowest digestibility coefficient, whereas leucine and glutamine showed the highests digestible amino acids values.

\section{INTRODUÇÃO}

A utilização de alimentos alternativos tem tomado cada vez mais espaço na alimentação de frangos de corte, principalmente pela produção restrita de milho, políticas reguladoras de estoque e de fatores climáti- cos em determinadas épocas do ano (Barcellos et al., 2006). Assim, uma das alternativas é o uso de silagem na alimentação de aves, pois de acordo com Gobetti et al. (2013) uma das vantagens da silagem na alimentação animal é que esta se apresenta como uma fonte 
de suplementação energética aos animais. Entretanto, poucos estudos são feitos com o fornecimento da silagem para frangos.

Sartori et al.(2002), ao analisarem a silagem de grão úmidos de milho na alimentação de frangos de corte, constataram que esse alimento pode ser um bom ingrediente em dietas para frangos até os 21 dias de idade, não afetando o peso final das aves, o rendimento de carcaça e peso dos órgãos.

Em pesquisa com frangos de corte criados em sistemas convencional e alternativo (orgânico), alimentados com silagem de grãos úmidos de milho em substituição ao milho seco da ração, Gonçalves et al. (2005) concluíram que a silagem de grãos úmidos de milho pode substituir em até $60 \%$ o milho seco, nas dietas de frangos de corte, sem comprometer o desempenho, o rendimento de carcaça e os cortes, para os dois sistemas.

$\mathrm{Na}$ formulação de rações para frangos de corte, o conhecimento da composição química e os valores energéticos dos alimentos torna-se necessário, além do teor de aminoácidos digestíveis, uma vez que estes compõem a proteína dos alimentos empregados nas rações para os animais (Gomes et al., 2010).

Nesse contexto, o objetivo deste estudo foi determinar os valores energéticos e de aminoácidos da silagem de grãos úmidos de milho na alimentação de frangos de corte.

\section{MATERIAIS E MÉTODOS}

Todos os procedimentos experimentais foram previamente aprovados pelo Comitê de Ética no Uso de Animais em Experimentação (Parecer CEUA/ UNIOESTE $n^{\circ}$ 036/2013). Foram realizados dois ensaios na Fazenda Experimental da Universidade Estadual do Oeste do Paraná-UNIOESTE, Marechal Cândi-

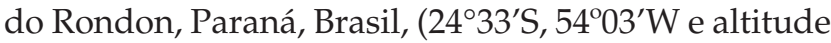
de 410 metros), no período de fevereiro a março de 2014.

Para a determinação dos valores energéticos da silagem de grãos úmidos de milho (SGUM), foram utilizados 120 frangos de corte machos, linhagem Cobb Slow, de 21 a 31 dias de idade, com peso médio inicial de $765,0 \pm 1,7 \mathrm{~g}$, distribuídos em um delineamento inteiramente casualizado, com cinco tratamentos (ração referência-RR e níveis de substituição da SGUM de $10,20,30$ e $40 \%$ ), seis repetições e quatro aves por unidade experimental. A RR foi formulada à base de milho, farelo de soja, óleo vegetal, vitaminas, minerais e aditivos, para atender às exigências nutricionais dos animais de 21 a 35 dias de idade, de acordo com as recomendações de Rostagno et al. (2011).

As aves foram criadas em galpão de alvenaria até os 21 dias de idade, recebendo ração comercial, e então foram transferidas às gaiolas metabólicas com dimensões de $50 \times 50 \mathrm{~cm}$, providas de bebedouros tipo nipple e comedouros individuais por gaiola. O período experimental teve duração de dez dias, sendo cinco dias de adaptação e cinco dias de coleta. $\mathrm{O}$ fotoperíodo empregado foi o de 24 horas de luz.
O método de análise foi o de coleta total de excretas. As bandejas metálicas foram revestidas com plástico e as coletas foram realizadas duas vezes ao dia, às 8:00 h e 18:00 h, para evitar a fermentação, sendo que as amostras coletadas eram acondicionadas em sacos plásticos identificados e armazenadas em freezer a $-18^{\circ} \mathrm{C}$, conforme metodologia descrita por Sakomura e Rostagno (2007).

As amostras das excretas e SGUM foram pré-secas em estufa com circulação forçada de ar, a $55^{\circ} \mathrm{C}$ durante 72 horas, assim como as amostras da RR, e posteriormente foram analisadas para determinação de matéria seca (MS), proteína bruta (PB) e energia bruta (EB). Além dessas análises, a SGUM também foi submetida à determinação de extrato etéreo (EE), matéria mineral (MM), fibra em detergente neutro (FDN) e fibra em detergente ácido (FDA), de acordo com as técnicas descritas por Silva e Queiroz (2002).

Ao término do experimento, foram determinadas a quantidade de ração consumida por unidade experimental e a quantidade total de excretas produzidas. A partir dos resultados das análises laboratoriais, foram determinados os valores de energia metabolizável aparente (EMA) e EMA corrigida para o balanço de nitrogênio (EMAn) da SGUM, por meio das equações propostas por Matterson et al. (1965). Após, foram calculados os coeficientes de metabolizabilidade da EMA (CMA) e da EMAn (CMAn), com a finalidade de avaliar a eficiência de utilização da energia bruta como energia metabolizável pelas aves.

No segundo experimento, foram utilizados 12 galos Leghorn adultos (60 dias), cecectomizados, com peso médio de 1912,10 $\pm 133,73 \mathrm{~g}$. Os animais foram alojados em gaiolas metabólicas individuais $(50 \times 50 \mathrm{~cm})$ e submetidos a um período de adaptação de cinco dias, recebendo como alimentação uma ração formulada à base de milho e farelo de soja para atender às exigências de frangos de corte em crescimento, segundo Rostagno et al. (2011), em dois turnos de uma hora, às 8:00 h e 17:00 h, visando à dilatação do inglúvio.

Após a adaptação, os animais foram mantidos em jejum por $24 \mathrm{~h}$, para esvaziamento do trato digestório, e posteriormente seis dos doze galos foram forçados a ingerir a SGUM. Cada galo foi alimentado com $30 \mathrm{~g}$ do alimento, dividido em duas porções de 15 gramas cada, às 8:00 h e 18:00 h, a fim de evitar regurgitações. Simultaneamente, seis galos permaneceram em jejum, para determinação das perdas endógenas e metabólicas dos aminoácidos. As 56 horas restantes após a primeira alimentação compreenderam o período de coletas de excretas, que foram realizadas duas vezes por dia (8:00 h e 18:00 h) para evitar possíveis fermentações, utilizando-se bandejas metálicas revestidas com plástico sob o piso das gaiolas.

Ao final do período de coleta de excretas, o material foi quantificado, homogeneizado e seco em estufa de ventilação forçada por $72 \mathrm{~h}$ a $50^{\circ} \mathrm{C}$. Após a secagem e moagem, foi determinada a MS e o $\mathrm{N}$ das excretas e da SGUM, enquanto o perfil de aminoácidos essenciais, após liofilização da digesta, foi determinado por cromatografia líquida de alta performance. 
Tabela I. Valores médios de matéria seca, energia bruta, proteína bruta, matéria mineral, fibra em detergente neutro, fibra em detergente ácido e extrato etéreo da SGUM (matéria natural) (Average values of dry matter, crude energy, crude protein, mineral matter, neutral detergent fiber, acid detergent fiber and ether extract of SGUM (as fed basis)).

\begin{tabular}{lc}
\hline Variáveis & Quantidade \\
\hline Matéria seca (\%) & 63,30 \\
Energia bruta (kcal/kg) & 4241 \\
Proteína bruta (\%) & 8,68 \\
Matéria mineral (\%) & 1,50 \\
Fibra em detergente neutro (\%) & 15,79 \\
Fibra em detergente ácido (\%) & 3,79 \\
Extrato etéreo (\%) & 2,73 \\
\hline
\end{tabular}

SGUM= Silagem de grãos úmidos de milho.

Os valores obtidos no tratamento-jejum foram utilizados para realizar as correções correspondentes às perdas metabólicas e endógenas dos aminoácidos. Conhecendo-se as quantidades de aminoácidos ingeridos e excretados, bem como a fração metabólica e endógena obtida com galos em jejum, foram determinados os coeficientes de digestibilidade verdadeira e o conteúdo digestível verdadeiro dos aminoácidos no alimento, por meio da fórmula proposta por Rostagno e Featherston (1977), para os diferentes tratamentos.

Os dados obtidos foram submetidos à análise de variância $(\mathrm{p}<0,05)$ e posterior análise de regressão polinomial $(\mathrm{p}<0,05)$, por meio do PROC GLM do pacote estatístico SAS® (SAS, 2001).

\section{RESULTADOS E DISCUSSÃO}

A SGUM apresentou valores de MS, EB, PB, MM, FDN, FDA e EE, respectivamente, de 63,30\%; $4241 \mathrm{kcal} / \mathrm{kg}, 8,68 \% ; 1,50 \% ; 15,79 \% ; 3,79 \%$ e $2,73 \%$; com base na matéria natural (tabela I). A composição bromatológica da SGUM foi semelhante à obtida por Igarazi et al. (2008) e Nunes et al. (2008).

Quanto à EMA, os resultados foram superiores aos valores encontrados para $\mathrm{EMA}_{\mathrm{n}}$ (tabela II). Esta variação pode ter ocorrido devido a vários fatores, entre os quais o teor de MS no momento da ensilagem, teor de glicídios solúveis, poder tampão, a espécie bacte- riana predominante e a velocidade de fermentação (Andrigueto et al., 2002). Os valores de energia metabolizável e os coeficientes de metabolizabilidade apresentaram efeito linear decrescente $(p<0,05)$ em função do aumento dos níveis de inclusão da SGUM (tabela II). Entretanto, todos os valores determinados foram superiores a $80 \%$ de aproveitamento da EB, resultando em um alimento de alto valor energético para aves. Os resultados encontrados para CMA e CMA $\mathrm{C}_{\mathrm{n}}$ foram próximos aos obtidos por Nunes et al. (2008).

No que diz respeito ao coeficiente de digestibilidade de aminoácidos, a SGUM apresentou o menor coeficiente de digestibilidade para cistina $(60,54 \%)$ e o maior para a leucina $(87,21 \%)$, conforme dados expressos na tabela III. Quanto ao perfil de aminoácidos digestíveis da SGUM, a cistina apresentou o menor valor $(0,096 \%)$ e a glutamina o maior $(1,061 \%)$. Os coeficientes de digestibilidade dos aminoácidos e os aminoácidos digestíveis da SGUM são menores que os encontrados por Rostagno et al. (2011), Rodrigues et

Tabela III. Aminoácidos totais, coeficientes de digestibilidade e aminoácidos digestíveis da SGUM (matéria natural) (Total amino acids, coefficients of digestibility and digestible amino acids of SGUM (as fed basis)).

\begin{tabular}{lccc}
\hline Aminoácidos & AT & CD & AD \\
\hline Lisina & 0,168 & 69,13 & 0,116 \\
Treonina & 0,262 & 66,42 & 0,174 \\
Metionina & 0,135 & 77,17 & 0,104 \\
Cistina & 0,159 & 60,54 & 0,096 \\
Met+cis & 0,286 & 66,39 & 0,190 \\
Alanina & 0,573 & 80,07 & 0,459 \\
Arginina & 0,247 & 67,57 & 0,167 \\
Aspartato & 0,477 & 68,78 & 0,328 \\
Glutamina & 1,297 & 81,81 & 1,061 \\
Histidina & 0,207 & 69,68 & 0,144 \\
Isolecina & 0,271 & 70,23 & 0,190 \\
Leucina & 0,931 & 87,21 & 0,812 \\
Femilalanina & 0,414 & 70,06 & 0,290 \\
Serina & 0,318 & 66,91 & 0,213 \\
Valina & 0,366 & 74,26 & 0,272 \\
Glicina & 0,279 & 70,70 & 0,197 \\
Prolina & 0,725 & 82,65 & 0,599 \\
\hline
\end{tabular}

AT= Aminoácidos totais (\%); $C D=$ Coeficientes de digestibilidade (\%); $A D=$ Aminoácidos digestíveis (\%); SGUM= Silagem de grãos úmidos de milho.

Tabela II. Valores médios de energia metabolizável aparente (EMA), EMA corrigida pelo balanço de nitrogênio (EMAn), coeficiente de metabolizabilidade aparente (CMA) e CMA corrigido pelo balanço de nitrogênio (CMAn) de dietas com diferentes níveis de inclusão de SGUM, para frangos de corte de 21 a 31 dias de idade (matéria natural) (Average values of apparent metabolizable energy (EMA) and EMA corrected for nitrogen balance (EMAn), apparent metabolizability coefficient (CMA) and CMA corrected for nitrogen balance (CMAn) in diets with different levels of SGUM inclusion for broilers from 21 to 31 days old (as fed basis)).

\begin{tabular}{|c|c|c|c|c|c|c|c|}
\hline \multirow{2}{*}{ Variáveis } & \multicolumn{4}{|c|}{ Níveis de inclusão SGUM (\%) } & \multirow{2}{*}{ Equação de regressão $(\mathrm{Y})^{*}$} & \multirow{2}{*}{$\mathrm{R}^{2}$} & \multirow{2}{*}{ CV $(\%)$} \\
\hline & 10 & 20 & 30 & 40 & & & \\
\hline EMA (kcal/kg) & 2402 & 2196 & 2279 & 2254 & $Y=2372,95-3,60789 X$ & 0,29 & 3,42 \\
\hline EMAn (kcal/kg) & 2404 & 2194 & 2255 & 2234 & $Y=2383,63-4,47422 X$ & 0,40 & 2,65 \\
\hline CMA $(\%)$ & 89,48 & 81,81 & 84,88 & 83,98 & $Y=88,3976-0,134402 X$ & 0,29 & 3,42 \\
\hline CMAn (\%) & 89,55 & 81,72 & 84,01 & 83,23 & $Y=88,79555-0,166675 X$ & 0,40 & 2,65 \\
\hline
\end{tabular}

*Efeito linear ao nível de $5 \%$ de probabilidade. SGUM= Silagem de grãos úmidos de milho. 
al. (2001) e Fisher Jr. (1998) para milho, sendo que na literatura não são reportados os coeficientes de digestibilidade de aminoácidos e os teores de aminoácidos digestíveis da SGUM. Entretanto, as diferenças encontradas podem ser devidas principalmente à composição química do alimento, como teor de fibra e de proteína bruta, os quais podem alterar os coeficientes de digestibilidade (Fisher Jr. et al., 1998). De modo geral, apesar dos coeficientes de digestibilidade dos aminoácidos da SGUM não terem sido altos em relação ao milho, isso não representa um fator limitante, uma vez que podem ser usados aminoácidos sintéticos nas rações em que a SGUM for utilizada.

\section{CONCLUSÕES}

A silagem de grãos úmidos de milho (SGUM) apresentou valores médios de $2283 \mathrm{kcal} / \mathrm{kg}$ de EMA e 2272 $\mathrm{kcal} / \mathrm{kg}$ de EMAn, sendo que os valores energéticos foram negativamente influenciados pelos níveis de inclusão da SGUM. A cistina apresentou o menor coeficiente de digestibilidade, enquanto a leucina e a glutamina apresentaram os maiores valores de aminoácidos digestíveis.

\section{BIBLIOGRAFIA}

Andriguetto, J.M.; Perly, L.; Minardi, I; Gemael, A.; Flemming, J.S.; Souza, G.A. e Bona Filho, A. 2002. Nutrição animal. As bases e os fundamentos da nutrição animal. Nobel. São Paulo.

Barcellos, L.C.G.; Furlan, A.C.; Murakami, A.E.; Silva, M.A.A. e Silva, R.M. 2006. Avaliação nutricional da silagem de grão úmidos de sorgo de alto ou de baixo conteúdo de tanino para frangos de corte. Rev Bras Zootecn, 35: 104-112.

Fischer Jr., A.A.; Albino, L.F.T.; Rostagno, H.S. e Gomes, P.C. 1998. Determinação dos coeficientes de digestibilidade e dos valores de aminoácidos de diferentes alimentos para aves. Rev Bras Zootecn, 27: $307-313$
Gobetti, S.T.C.; Neumann, M.; Oliboni, R. e Oliveira, M.R. 2013. Utilização de silagem de grão úmido na dieta de animais ruminantes. Ambiência, 9: 225-239.

Gonçalves, J.C.; Sartori, J.R.; Pezzato, A.C.; Costa, C.; Martinez, K.L.A.; Cruz, V.C.; Madeira, L.A. e Oliveira, H.N. 2005. Silagem de grãos úmidos de milho em substituição ao milho seco da ração de frangos de corte em dois sistemas. Pes Agr Bras, 40: 1021-1028.

Gomes, P.C.; Generoso, R.A.R.; Rostagno, H.S.; Albino, F.T.; Brumano, G. e Mello, H.H.C. 2010. Valores de aminoácidos digestíveis de alimentos para aves. Rev Bras Zootecn, 39: 1259-1265.

Igarasi, M.S.; Arrigoni, M.B.; Souza, A.A.; Silveira, A.C.; Martins, C.L. e Oliveira, H.N. 2008. Desempenho de bovinos jovens alimentados com dietas contendo grão úmido de milho ou sorgo. Rev Bras Zootecn, 37: 513-519.

Matterson, L.D.; Potter, L.M. e Stutz, M.W. 1965. The metabolizable energy of feed ingredients for chickens. Agr Exp Stat Res Rep, 7: 3-11.

Nunes, R.V.; Pozza, P.C.; Potença, A.; Nunes, C.G.V.; Pozza, M.S.S.; Lorençon, L.; Eyng, C. e Navarine, F.C. 2008. Composição química e valores energéticos do milho e da silagem de grãos úmidos de milho para aves. Rev Bras Saúde Prod An, 9: 82-90.

Rodrigues, P.H.M.; Senatore, A.L.; Andrade, S.J.T.; Ruzante, J.M.; Lucci, C.S. e Lima, F.R. 2002. Efeitos da adição de inoculantes microbianos sobre a composição bromatológica e perfil fermentativo da silagem de sorgo produzida em silos experimentais. Rev Bras Zootecn, 31: 2373-2379

Rostagno, H.S. e Featherston, W.R. 1977. Estudos de métodos para determinar a disponibilidade de aminoácidos em pintos. Rev Bras Zootecn, 6: 64-76.

Rostagno, H.S.; Albino, L.F.T.; Donzele, J.L.; Gomes, P.C.; Oliveira, R.F.; Lopes, D.C.; Ferreira, A.S.; Barreto, S.L.T. e Euclides, R.F. 2011 . Tabelas brasileiras para aves e suínos: composição de alimentos e exigências nutricionais. UFV. Viçosa.

Sakomura, N.K. e Rostagno, H.S. 2007. Métodos de pesquisa em nutrição de monogástricos. Funep. Jaboticabal. 283 pp.

SAS. 2001. SAS user's guide: statistical. Cary. NC. 438 pp.

Sartori, J.R.; Costa, C.; Pezzato, A.C.; Martins., C.L.; Carrijo, A.S.; Cruz, V.C. e Pinheiro, D.F. 2002. Silagem de grãos úmidos de milho na alimentação de frangos de corte. Pes Agr Bras, 37: 1009-1015.

Silva, D.J. e Queiroz, A.C. 2002. Análise de alimentos: métodos químicos e biológicos. UFV. Viçosa. 